MAGALHÃES, G.M., SILVEIRA, A.C.T. e ALESSI, A.C. Imunomarcação de micrometástases de neoplasias mamárias espontâneas em linfonodos de cadelas por meio do receptor CD44. PUBVET, Londrina, V. 6, N. 8, Ed. 195, Art. 1308, 2012.

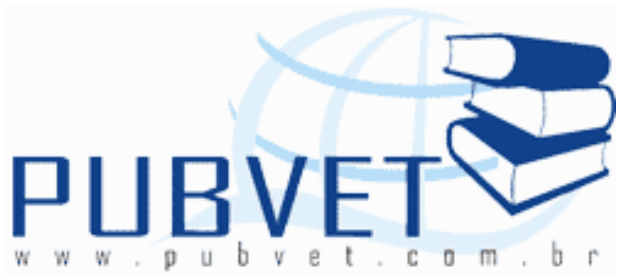

PUBVET, Publicações em Medicina Veterinária e Zootecnia.

\title{
Imunomarcação de micrometástases de neoplasias mamárias espontâneas em linfonodos de cadelas por meio do receptor CD44.
}

\section{Geórgia Modé Magalhães ${ }^{1}$, Ana Carolina Trompieri Silveira ${ }^{2}$, Antonio Carlos} Alessi $i^{3}$

${ }^{1}$ Doutoranda, Programa de Pós-graduação em Medicina Veterinária, Unesp Jaboticabal.

${ }^{2}$ Pesquisadora Universidade Federal de Sergipe.

${ }^{3}$ Docente, Departamento de Patologia Veterinária, Unesp Jaboticabal.

\section{Resumo}

O CD44 é uma molécula de adesão, multifuncional pertencente à família de glicoproteínas transmembranas e está intimamente relacionada com a progressão tumoral. Este trabalho teve como objetivos: avaliar a imunomarcação de CD44 nas neoplasias mamárias malignas da cadela, com e sem metástase em linfonodos regionais; associá-la como fator prognóstico na detecção precoce de metástase; relacioná-la com a imunomarcação de MMP-9, E-caderina e VEGF. Compuseram os grupos experimentais, cadelas com tumor mamário, com (Grupo M) ou sem metástase (Grupo N) detectável em linfonodos. As neoplasias mamárias foram classificadas de acordo com a Organização Mundial de Saúde. Para isso utilizou-se a técnica de imunohistoquímica, em amostras incluídas em parafina. Para a determinação da porcentagem de imunomarcação considerou-se somente as células epiteliais 
MAGALHÃES, G.M., SILVEIRA, A.C.T. e ALESSI, A.C. Imunomarcação de micrometástases de neoplasias mamárias espontâneas em linfonodos de cadelas por meio do receptor CD44. PUBVET, Londrina, V. 6, N. 8, Ed. 195, Art. 1308, 2012.

neoplásicas. Para o anticorpo CD44 contou-se as marcações em linfócitos T nos linfonodos dos dois grupos. As marcações em linfócitos T foram maiores no grupo $\mathrm{N}$ e menores no grupo $\mathrm{M}$. Observou-se aumento significativo na marcação do CD44 do sítio primário do tumor (células epiteliais neoplásicas) para a metástase, assim como nas marcações de MMP-9 e E-caderina. Concluiu-se que o CD44 pode atuar em conjunto com outras moléculas, tais como a MMP-9 e a E-caderina. Propõe-se que a detecção precoce de micrometástase seja feita em linfócitos $T$ nos linfonodos drenantes das neoplasias mamárias malignas de cadelas.

Palavras chave: tumor mamário canino, CD44, metástase, neoplasia, oncologia, cães.

\section{Immunostaining of micrometastases of spontaneous mammary neoplasias of bitches in lymph nodes through receptor CD44}

\section{Abstract}

The CD44 is an adhesion molecule, which belongs to the multifunctional family of transmembrane glycoproteins and is closely related to tumor progression. The aim of this study was to evaluate the immunostaining for CD44 in malignant mammary neoplasia of female dogs, with and without metastasis at the regional lymph nodes, assign it as a prognostic factor in early detection of metastases; relate it with the immunostaining for MMP-9, ecadherin and VEGF. The experimental groups were: dogs with mammary tumor, with (Group M) or without metastasis (Group N) detectable in lymph nodes. The mammary tumors were classified according to the World Health Organization. The technique of immunohistochemistry was used in paraffinembedded samples. To determine the percentage of immunostaining was considered only the neoplastic epithelial cells. For the CD44 antibody was used the immunostaining on $T$ lymphocytes in lymph nodes of both groups. The immunostaining on $\mathrm{T}$ lymphocytes were higher in 
MAGALHÃES, G.M., SILVEIRA, A.C.T. e ALESSI, A.C. Imunomarcação de micrometástases de neoplasias mamárias espontâneas em linfonodos de cadelas por meio do receptor CD44. PUBVET, Londrina, V. 6, N. 8, Ed. 195, Art. 1308, 2012.

group $\mathrm{N}$ and lower in group $\mathrm{M}$. There was significant increase in CD44 immunostaining in the site of the primary tumor (neoplastic epithelial cells) for metastasis, as well as the staining of MMP-9 and E-cadherin. It was concluded that CD44 may act together with other molecules, such as MMP9 and E-cadherin. It is proposed that early detection of micrometastasis is made on $\mathrm{T}$ lymphocytes in lymph nodes draining malignant mammary neoplasms in female dogs.

Keywords: canine mammary tumor, CD44, metastasis, neoplasia, oncology, dogs

\section{Introdução}

O CD44 é uma molécula de adesão, multifuncional pertencente à família de glicoproteínas transmembrana e está intimamente relacionada com a progressão tumoral (KLINGBEIL et al., 2009). Está envolvida nas interações célula a célula e entre a célula e a matriz (NAOR et al., 1997). O enfraquecimento do mecanismo de adesão celular é o pré-requisito básico para a ocorrência de metástase (POZDNYAKOVA et al., 2009), porém pouco se sabe sobre o mecanismo pelo o qual a molécula CD44 interfere nas metástases.

CD44 é codificada por um gene de 20 exons, sendo que os cinco primeiros e os cinco últimos são constantes e, 10 deles estão sujeitos a regiões variáveis com splicing alternativos de RNA nuclear (NAOR et al.,1997). Essa região de variabilidade da molécula confere várias isoformas de papéis diversos em suas estruturas e funções (GOTTE \& YIP 2006). Numerosas combinações dos exons variantes foram detectadas em mais de 30 diferentes isoformas relatadas em vários tipos de tecidos, na embriogênese, na linfohematopoese e na ativação leucocitária.

A matriz extracelular é formada por cadeias de polissacarídeos da classe denominada glicosaminoglicana, sendo um deles o ácido hialurônico (HA). Muitas funções do HA dependem de proteínas ligadoras, algumas das quais são componentes da matriz extracelular e outras da superfície de células. A função 
MAGALHÃES, G.M., SILVEIRA, A.C.T. e ALESSI, A.C. Imunomarcação de micrometástases de neoplasias mamárias espontâneas em linfonodos de cadelas por meio do receptor CD44. PUBVET, Londrina, V. 6, N. 8, Ed. 195, Art. 1308, 2012.

do HA é manter a hidratação e integridade estrutural do tecido (HAMILTON et al., 2007). O CD44 é o principal receptor de superfície celular para o HA (SHERIDAN et al., 2006; HAMILTON et al., 2007). Em um estudo com carcinomas mamários invasivos, concluiu-se que as linhagens celulares deste tumor produziam HA endógeno, possivelmente aumentando a rapidez da motilidade dessas células (HAMILTON et al., 2007).

Yin \& Qin (2003) demonstraram em estudos experimentais que altos níveis de E-caderina podem inibir a ligação do CD44 com o HA, diminuindo assim a motilidade celular. O CD44 também sinaliza a célula a se ligar com receptores da MMP (HAMILTON et al., 2007). Kuo et al., (2009) trataram linhagens celulares de tumores mamários (MDA-MB-435s) com TGF-beta e obtiveram um aumento da sinalização para as MMP nas membranas celulares. Com o aumento das MMPs também se observou um aumento do CD44 e assim houve uma maior invasividade de células cancerígenas. PACOR et al. (2004) realizaram tratamentos intratumorais com NAMI-A, um metal com propriedades eficientes contra metástases pulmonares de tumores sólidos em ratos. Esta droga reduziu a expressão de CD44, a qual diminuiu a modulação de MMP-9 interferindo nas propriedades malignas das células tumorais em degradar a matriz extracelular, invasão e disseminação metastática.

A ligação entre o CD44 e o ácido HA está envolvida com a morfogênese, a inflamação e a invasão tumoral. Abbas et al. (2000) relataram que o papel da molécula de adesão CD44 na resposta inflamatória está relacionado com a migração e a indução de memória em células $T$. Os linfócitos $T$, os quais especificamente reconhecem antígenos, recebem sinais desses receptores antigênicos, com aumento da afinidade das integrinas por seus ligantes. $O$ CD44 tem sido envolvido na produção de citocinas, tais como a interleucina 8 e o fator de crescimento de fibroblastos.

Estes fatos indicam que o CD44 possui um papel importante na emissão de sinais oncogênicos em neoplasias mamárias (BOURGUIGNON et al., 2003). O receptor CD44 é expresso em tecidos normais e há muitas variantes deste receptor, sendo a CD44v6 superexpressa em tumores de mama da mulher 
MAGALHÃES, G.M., SILVEIRA, A.C.T. e ALESSI, A.C. Imunomarcação de micrometástases de neoplasias mamárias espontâneas em linfonodos de cadelas por meio do receptor CD44. PUBVET, Londrina, V. 6, N. 8, Ed. 195, Art. 1308, 2012.

(DIAZ et al., 2005). Combinações contendo exon $6 \mathrm{v}$ parecem ter uma grande importância em disseminações de carcinomas pancreáticos em ratos, em linfoma não Hodgkin humano e carcinoma de cólon, também em carcinoma mamário (FRIEDRICHS et al., 1995, HEBBARD et al.,2000).

Em cães, o comportamento da molécula de adesão CD44 foi relatado por Madrazo et al. (2009) o qual limita seu uso como um marcador de malignidade em tumores de mama canino. Paltian et al. (2009) associa a maior marcação de CD44 com tumores benignos ou com tumores mamários caninos que tenham comportamentos relativamente benignos.

A detecção precoce de metástase está diretamente ligada ao fator prognóstico. Harrell et al. (2006) mostram que o CD44 é expresso em tumores primários e superexpresso em êmbolos tumorais linfáticos e metástases, concluindo que as subpopulações de CD44 no sítio primário são preferencialmente atraídas para os vasos linfáticos tumorais e seus linfonodos.

Este estudo tem como objetivo avaliar a imunomarcação de receptor CD44 em linfonodos drenantes de tumores mamários caninos, relacionando-o com o tempo de sobrevida. Objetiva-se também quantificar a marcação do CD44 em linfócitos $T$ nos linfonodos de cadelas com neoplasia mamária e cadelas com neoplasias mamárias com metástase em linfonodo. Outras moléculas envolvidas no processo de metástase como o VEGF, as metaloproteinases da matriz (MMP-9) e E-caderina foram usadas como auxílio da compreensão da patogênese do CD44 nas metástases. O entendimento da molécula de adesão como um marcador prognóstico auxiliará nas detecções precoces de micrometástases continuando o estudo comparativo entre as neoplasias mamárias de cadelas e de mulheres.

\section{Material e métodos}

Compuseram os grupos experimentais cadelas com tumor mamário, com ou sem metástase visível em linfonodos. Não houve predileção por localização mamária, mas utilizou-se mais as mamas inguinais e linfonodos inguinais. 
MAGALHÃES, G.M., SILVEIRA, A.C.T. e ALESSI, A.C. Imunomarcação de micrometástases de neoplasias mamárias espontâneas em linfonodos de cadelas por meio do receptor CD44. PUBVET, Londrina, V. 6, N. 8, Ed. 195, Art. 1308, 2012.

Grupo $N, n=10$, neoplasia mamária e linfonodo sem metástase visível em microscopia de luz; Grupo M, $n=10$, neoplasia mamária e linfonodos com metástases observadas microscopicamente.

Os fragmentos de áreas significativas dos tumores mamários e de linfonodos drenantes foram adquiridos do Serviço de Reprodução e Obstetrícia Veterinária, do Hospital Veterinário "Governador Laudo Natel", da FCAV UNESP, Jaboticabal, SP e de clínicas particulares. Foram consideradas como critérios de avaliação as dimensões do tumor, a sua relação com o tecido adjacente (presença de cápsula, séssil ou pediculado), a presença de úlceras, de hemorragia, de secreções ou de exsudato inflamatório.

O aspecto macroscópico de cada neoplasia foi avaliado e os fragmentos colhidos fixados em solução de formol a $10 \%$, tamponado com fosfatos, $\mathrm{pH} 7,4$ e processados rotineiramente até a inclusão em parafina. Cortes de $5 \mu$ foram feitos em micrótomo e posteriormente corados pelo método da Hematoxilina e Eosina. O processamento histológico foi feito no Departamento de Patologia Veterinária (FCAV-UNESP), Câmpus de Jaboticabal - SP.

$\mathrm{Na}$ análise microscópica em microscopia de luz, foi feita a classificação da neoplasia, segundo os critérios da Organização Mundial da Saúde (MISDORP et al. 1999), avaliou-se o grau de diferenciação celular, o pleomorfismo, a anaplasia, a presença de figuras de mitose, de êmbolos em vasos sangüíneos e em linfáticos, a invasão do tecido adjacente e de metástases em linfonodos. Após a classificação, apenas os carcinomas foram utilizados neste experimento para uma melhor comparação entre a espécie canina e humana, já que os tumores mesenquimais e mistos são raros na espécie humana. O grau de malignidade em cadelas foi proposto por Misdorp (1999), associando as formações de túbulos, hipercromatismo, mitoses e pleomorfismo nuclear.

A técnica imuno-histoquímica empregada foi o complexo estreptavidina peroxidase $(A B C)$, desenvolvido por HSU et al. (1981), com ligeiras modificações. Os anticorpos primários foram utilizados conforme a tabela 1 . Como controle positivo foram usadas glândulas mamárias normais que se encontravam ao redor da neoplasia e como controle negativo usou-se PBS ao 
MAGALHÃES, G.M., SILVEIRA, A.C.T. e ALESSI, A.C. Imunomarcação de micrometástases de neoplasias mamárias espontâneas em linfonodos de cadelas por meio do receptor CD44. PUBVET, Londrina, V. 6, N. 8, Ed. 195, Art. 1308, 2012.

invés do anticorpo primário. As marcações foram consideradas positivas quando a membrana plasmática e ou o citoplasmas apresentavam-se marcados. Para se quantificar a freqüência da imunomarcação, foram aleatoriamente selecionados quatro campos por corte e, foi contado um total de 100 células entre as marcadas e não marcadas na objetiva de 40x.

Tabela 1: Anticorpos utilizados em tecidos de neoplasmas mamários, tecidos mamários normais, linfonodos com metástases e linfonodos normais de cadelas.

\begin{tabular}{|c|c|c|c|}
\hline Anticorpos anti & Clones & Diluições & Procedência \\
\hline CD44v6 (M)* & DF1485 & $1: 50$ & DAKO, ref. M7082 \\
\hline VEGF (M) & VG-1 & $1: 300$ & $\begin{array}{c}\text { Abcam, ref. ab1316- } \\
100\end{array}$ \\
\hline E-caderina (M) & $4 \mathrm{~A} 2 \mathrm{C7}$ & $1: 100$ & $\begin{array}{c}\text { Zymed Lab., ref. 33- } \\
4000\end{array}$ \\
\hline $\begin{array}{l}\text { Metaloproteinasease } \\
(\mathrm{MMP})(\mathrm{P})\end{array}$ & 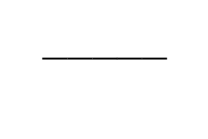 & $1: 200$ & DAKO, ref A0150 \\
\hline
\end{tabular}

Análise estatística

Foram verificadas as pressuposições básicas para a realização da análise de variância. Assim, a variável CD44 foi submetida à transformação logarítmica. Médias por classe de idade foram comparadas pelo teste de Tukey $(p<0,05)$.

Foi aplicado o teste $\mathrm{T}$ para comparação de resultados entre os grupos $\mathrm{N}$ (nas células epiteliais mamárias neoplásicas) e M (células epiteliais neoplásicas mamárias metastáticas) para cada anticorpo: CD44, E-caderina, MMP e VEGF. Também, compararam-se por esse mesmo teste no grupo $M$ as células 
MAGALHÃES, G.M., SILVEIRA, A.C.T. e ALESSI, A.C. Imunomarcação de micrometástases de neoplasias mamárias espontâneas em linfonodos de cadelas por meio do receptor CD44. PUBVET, Londrina, V. 6, N. 8, Ed. 195, Art. 1308, 2012.

marcadas no sítio primário do tumor e suas respectivas metástases em todos os anticorpos citados acima. E somente para o anticorpo anti-CD44 analisou-se por esse mesmo teste os linfócitos $\mathrm{T}$ marcados nos grupos $\mathrm{N}$ e $\mathrm{M}$.

A associação entre metástase e tipo histológico, grau de malignidade e tempo de sobrevida foi verificada pelo Teste Exato de Fisher.

As análises estatísticas foram conduzidas utilizando o programa computacional SAS (SAS 9.1, SAS Institute, Cary, NC, USA).

\section{Resultados}

Todas as células epiteliais glandulares mamárias normais foram imunomarcadas para o CD44, 100\% marcadas. Houve um aumento significativo em relação ao grupo $N$ para o grupo $M(p<0,05)$. $E$ também aumento significativo das contagens de células do sítio primário em relação à respectiva metástase. No sítio primário do tumor, observou-se poucas marcações em relação ao local da metástase. Em carcinomas simples túbulopapilíferos observou-se marcações mais intensas nos túbulos mais próximos dos normais e nas camadas mais externas de células nas papilas. Dois dos quatro carcinomas sólidos apresentaram pouca marcação no sítio primário. As células neoplásicas em vasos linfáticos, em sua maioria, estavam agrupadas e mesmo as que se encontravam isoladas estavam marcadas para o anticorpo CD44. Nos linfonodos as células marcadas estavam agrupadas em sua maioria nos seios subcapsulares e, em apenas dois casos elas invadiram o linfonodo pelos cordões linfáticos atingindo a região medular (Figura 1).

As médias e seus respectivos desvios padrões de cada anticorpo estão representados na tabela 2 .

No anticorpo CD44 foram realizadas contagens nos linfonodos dos dois grupos, observando a marcação em linfócitos T (Figura 2). A média de células marcadas no grupo $\mathrm{N}$ foi de $24,4 \pm 11,9$ e a média para o grupo $\mathrm{M}$ foi de $8,9 \pm$ 8,9 , sendo significativa essa diferença $(p<0,05)$. Foi aplicado o teste $T$, onde houve aumento significativo da marcação no sitio primário do tumor para a metástase. 
MAGALHÃES, G.M., SILVEIRA, A.C.T. e ALESSI, A.C. Imunomarcação de micrometástases de neoplasias mamárias espontâneas em linfonodos de cadelas por meio do receptor CD44.

PUBVET, Londrina, V. 6, N. 8, Ed. 195, Art. 1308, 2012.

Tabela 2 - Médias percentuais e desvio-padrão das contagens das células imunomarcadas pelos respectivos anticorpos nos dois grupos analisados.

\begin{tabular}{lccc}
\hline ANTICORPOS & N & M & $\begin{array}{c}\text { Sítio Primário } \\
\text { da metástase }\end{array}$ \\
E-caderina & $* 61,20 \pm 22,10$ & $* 90,00 \pm 17,95$ & $* 61,5 \pm 19,55$ \\
MMP-9 & $61,70 \pm 17,53$ & $* 77,50 \pm 16,73$ & $* 60,9 \pm 13,34$ \\
VEGF & $78,50 \pm 16,05$ & $83,20 \pm 15,51$ & $79,30 \pm 13,22$ \\
CD44 & $* 41,30 \pm 14,82$ & $* 73,70 \pm 13,50$ & $* 43,2 \pm 17,5$ \\
\hline
\end{tabular}

No grupo $\mathrm{N}$ foram encontrados cinco carcinomas complexos, três carcinomas simples padrão túbulo-papilífero e dois padrões sólidos. Os graus de malignidade foram três tumores grau I, quatro grau II e três grau III. A idade variou entre 6 e 15 anos. As raças foram três cães sem raça definida, dois poodles, dois pastores alemães, um cocker spaniel, boxer e teckel. O tempo de sobrevida foi considerado a partir da data da cirurgia, sendo mais de 20 meses a maioria. Apenas uma cadela veio a óbito um mês após a cirurgia. Uma das cadelas era ovariectomizada. Em relação ao grupo $M$ as classificações histológicas foram seis carcinomas simples padrão túbulo-papilífero, e quatro padrão sólido. Oito tumores foram classificados como grau II e dois tumores grau III. A idade variou entre 6 e 13 anos. As raças desses cães foram quatro teckel, três sem raça definida, um poodle, um beagle e um boxer. Três cadelas vieram a óbito no momento da cirurgia, quatro delas vieram a óbito um mês, quatro meses, 12 meses e 14 meses após a cirurgia. Duas estavam vivas após 19 meses. Todas as cadelas eram inteiras.

Em análise de variância, as variáveis E-caderina, MMP, VEGF e CD44 foram comparadas nos grupos $\mathrm{M}$ e $\mathrm{N}$ e com as idades dos animais. Os resultados foram significativos quando $\mathrm{P}<0,05$. As variáveis $\mathrm{E}$-caderina e MMP9 foram significativas em relação à metástase. A variável VEGF não apresentou 
MAGALHÃES, G.M., SILVEIRA, A.C.T. e ALESSI, A.C. Imunomarcação de micrometástases de neoplasias mamárias espontâneas em linfonodos de cadelas por meio do receptor CD44. PUBVET, Londrina, V. 6, N. 8, Ed. 195, Art. 1308, 2012.

diferenças significativas entre os grupos. Em relação ao CD44, este foi significativo tanto em relação ao grupo da metástase quanto em relação às idades dos animais. As idades significativas para o CD44 metastático foram 6, 8,9 , e 12 anos.

O tipo histológico, grau de malignidade e tempo de sobrevida não foram significativos para a metástase entre os grupos avaliados.

Em relação ao anticorpo E-caderina houve aumento significativo $(p<0,05)$ da marcação do grupo N (Figura 3 ) em relação ao grupo M (Figura 4). Quando se comparou o sítio primário do tumor no grupo $M$ com a sua respectiva metástase também houve um aumento significativo nas contagens das células marcadas.

Para o anticorpo MMP-9 não houve diferenças significativas $(p>0,05)$ em relação aos grupos $\mathrm{M}$ e $\mathrm{N}$ (Figura 5 ). Entretanto, quando se analisou o sítio primário do tumor para sua respectiva metástase houve um aumento significativo

Para o VEGF não houve diferenças significativas em relação aos grupos M e N. Também não se observou diferenças significativas entre o sítio primário e a metástase (Figura 6). 
MAGALHÃES, G.M., SILVEIRA, A.C.T. e ALESSI, A.C. Imunomarcação de micrometástases de neoplasias mamárias espontâneas em linfonodos de cadelas por meio do receptor CD44. PUBVET, Londrina, V. 6, N. 8, Ed. 195, Art. 1308, 2012.

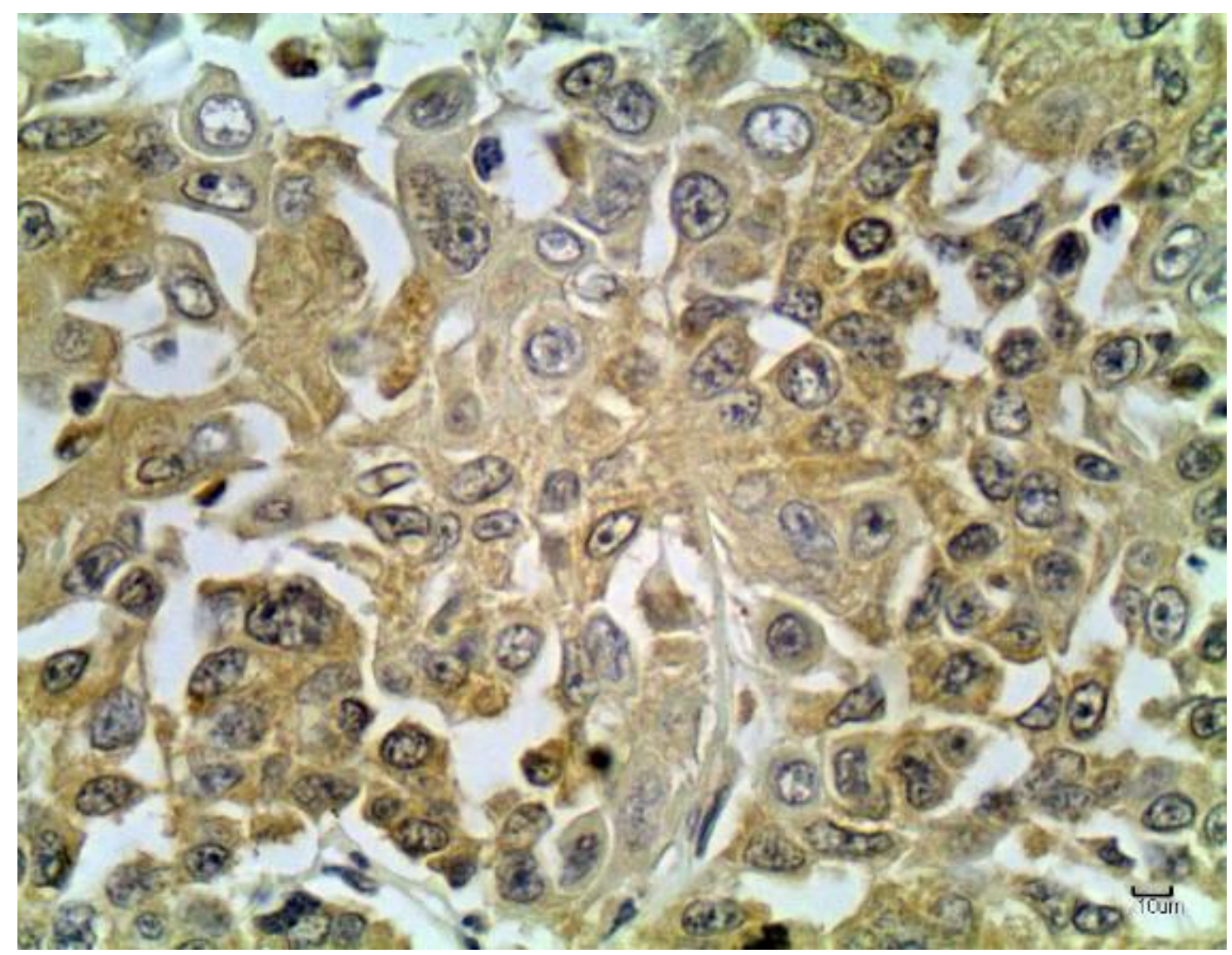

Figura 1: Metástase de células neoplásicas mamárias em linfonodo (Grupo M). As células indiferenciadas estão marcadas. Marcação imuno-histoquímica para CD44 em membrana plasmática e citoplasma de células epiteliais neoplásicas. Cromógeno DAB e contracoloração com Hematoxilina de Harris. Obj. 40x. 
MAGALHÃES, G.M., SILVEIRA, A.C.T. e ALESSI, A.C. Imunomarcação de micrometástases de neoplasias mamárias espontâneas em linfonodos de cadelas por meio do receptor CD44. PUBVET, Londrina, V. 6, N. 8, Ed. 195, Art. 1308, 2012.

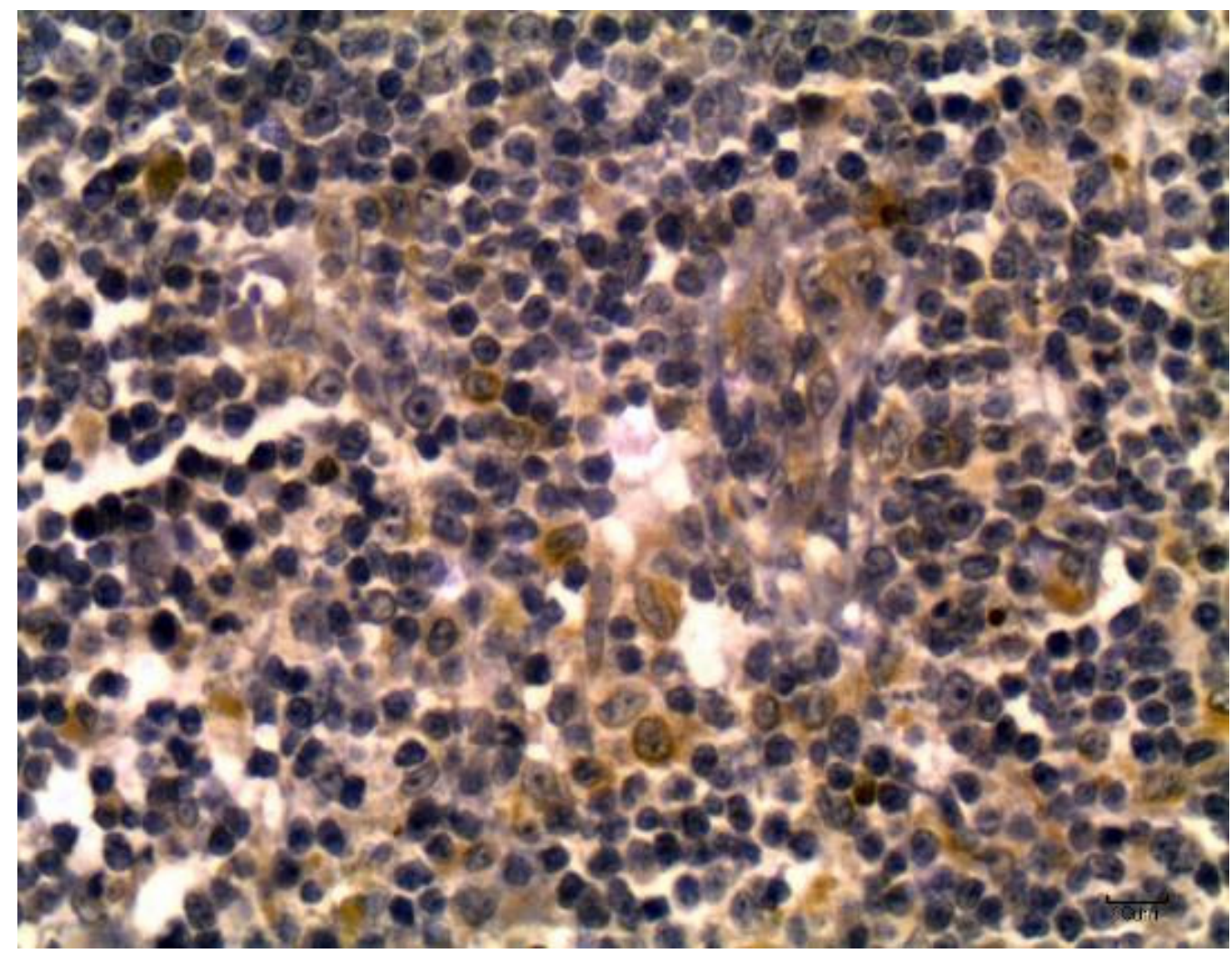

Figura 2: Linfonodo do grupo $\mathrm{N}$, sem metástase visível de células epiteliais mamárias. Notar marcações em linfócitos T. Marcação imuno-histoquímica para CD44 em membrana plasmática e citoplasma de células epiteliais neoplásicas. Cromógeno DAB e contracoloração com Hematoxilina de Harris. Obj. 40x. 
MAGALHÃES, G.M., SILVEIRA, A.C.T. e ALESSI, A.C. Imunomarcação de micrometástases de neoplasias mamárias espontâneas em linfonodos de cadelas por meio do receptor CD44. PUBVET, Londrina, V. 6, N. 8, Ed. 195, Art. 1308, 2012.

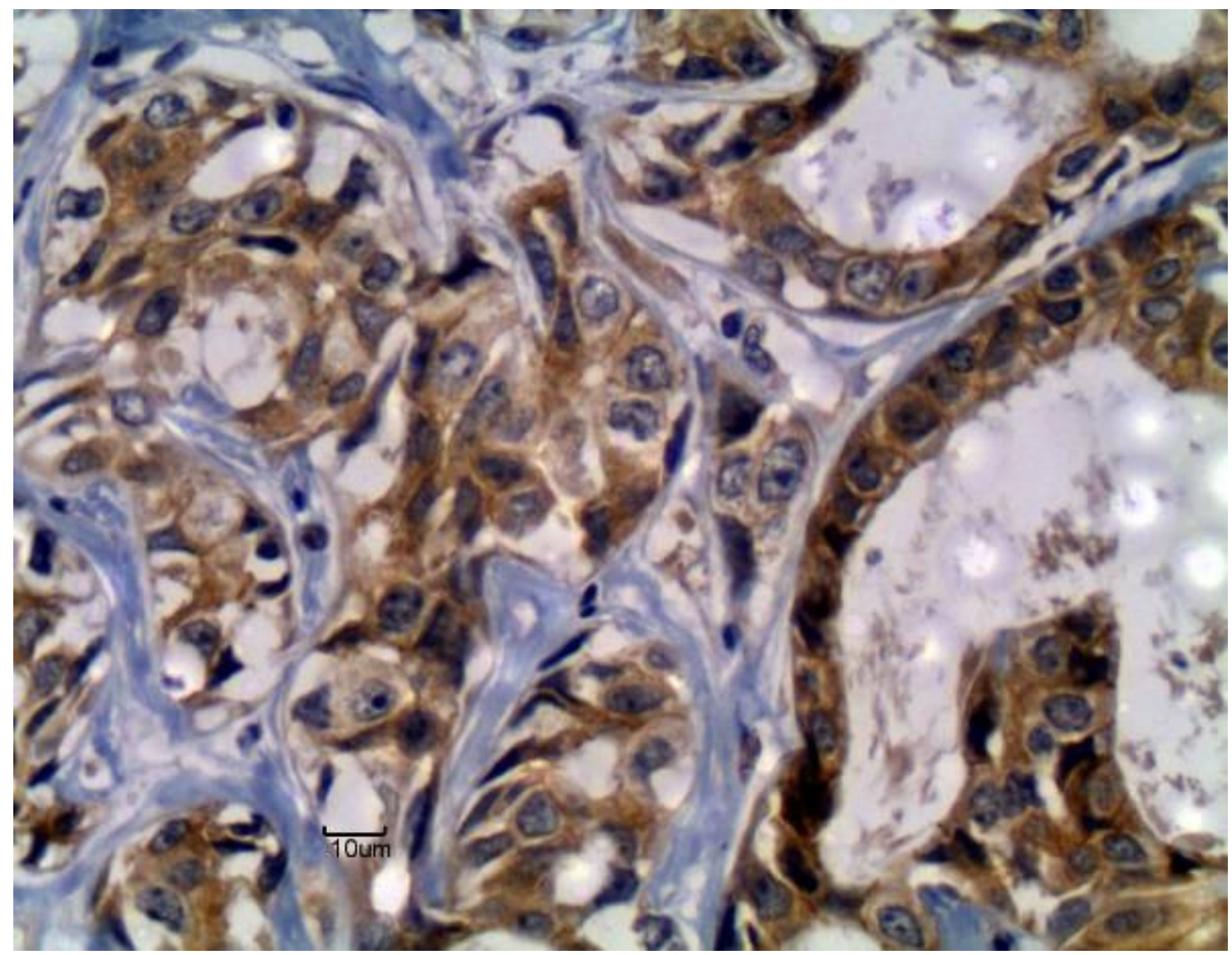

Figura 3: Neoplasia mamária de cadela sem metástase em linfonodo (Grupo N), Marcação imuno-histoquímica para E-caderina, observada na membrana plasmática e no citoplasma de células epiteliais neoplásicas. Cromógeno DAB e contracoloração com Hematoxilina de Harris. Obj. 40x 
MAGALHÃES, G.M., SILVEIRA, A.C.T. e ALESSI, A.C. Imunomarcação de micrometástases de neoplasias mamárias espontâneas em linfonodos de cadelas por meio do receptor CD44. PUBVET, Londrina, V. 6, N. 8, Ed. 195, Art. 1308, 2012.

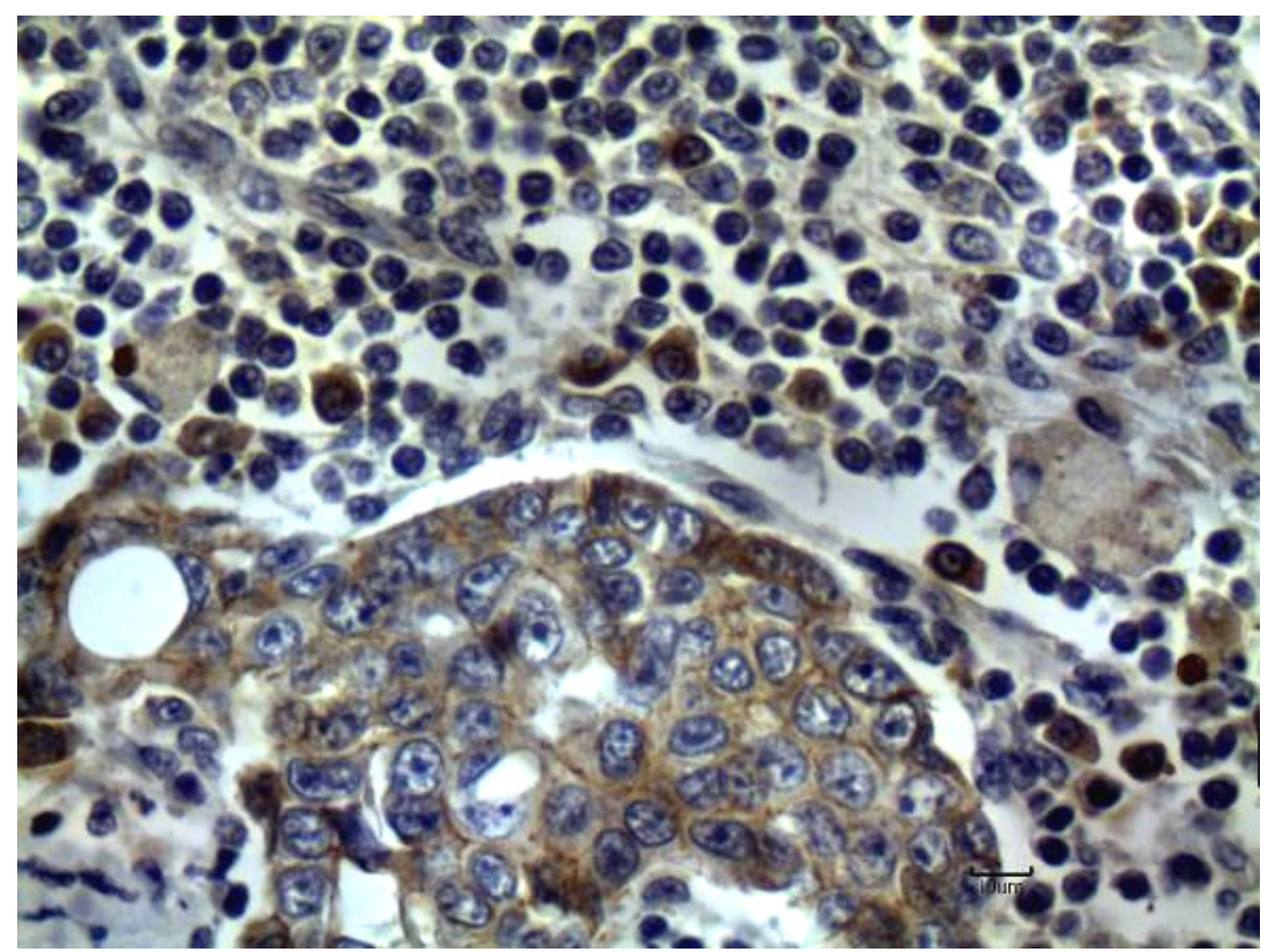

Figura 4: Neoplasia mamária metastática de cadela em linfonodo regional (Grupo M). Marcação imuno-histoquímica para E-caderina, observada em membrana plasmática e citoplasma de células epiteliais neoplásicas. Cromógeno DAB e contracoloração com Hematoxilina de Harris. Obj. 40x. 
MAGALHÃES, G.M., SILVEIRA, A.C.T. e ALESSI, A.C. Imunomarcação de micrometástases de neoplasias mamárias espontâneas em linfonodos de cadelas por meio do receptor CD44. PUBVET, Londrina, V. 6, N. 8, Ed. 195, Art. 1308, 2012.

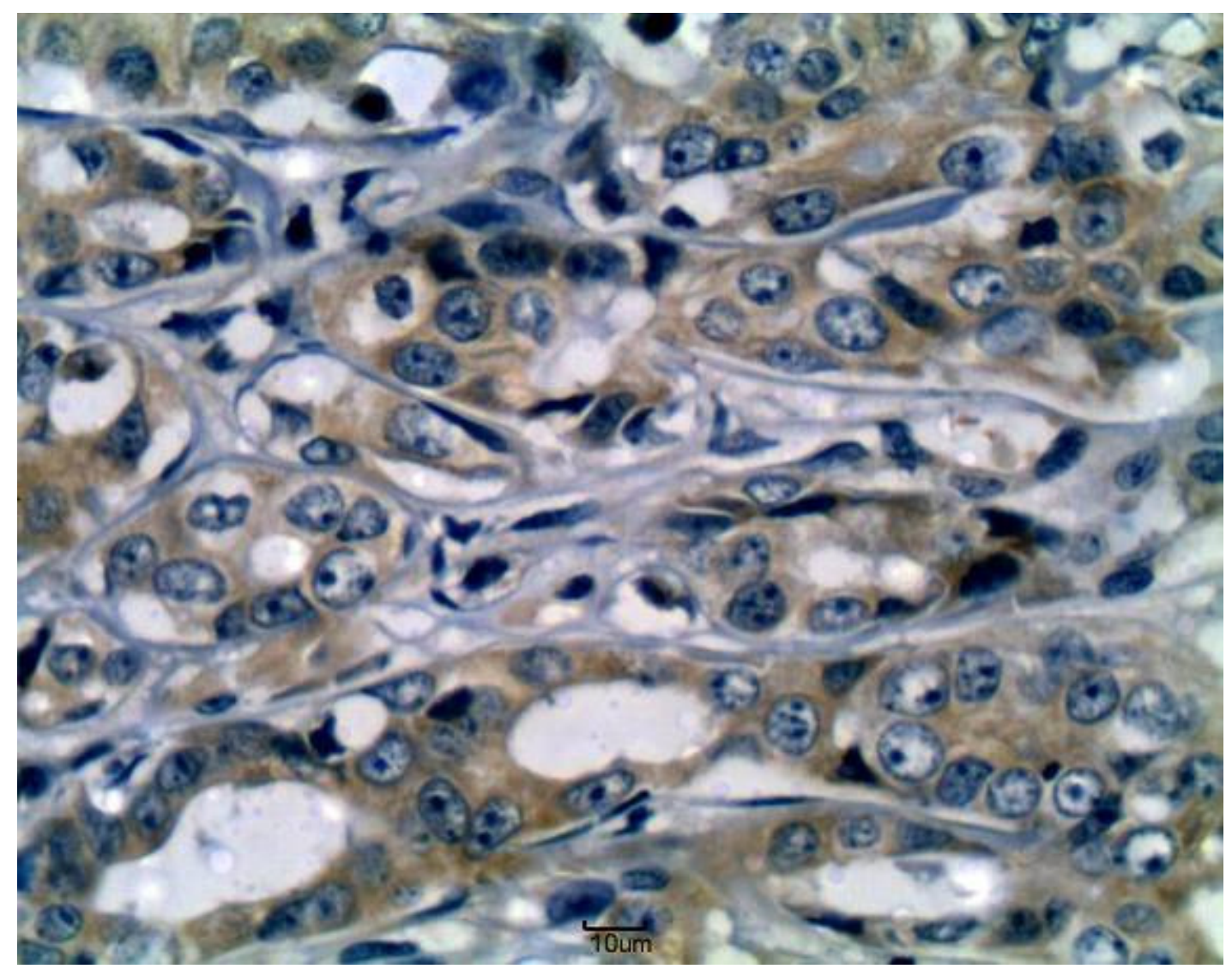

Figura 5: Neoplasia mamária sem metástase em linfonodo de cadela (Grupo N), Marcação imuno-histoquímica para MMP-9 em citoplasma de células epiteliais neoplásicas. Cromógeno DAB e contracoloração com Hematoxilina de Harris. Obj. 40x. 
MAGALHÃES, G.M., SILVEIRA, A.C.T. e ALESSI, A.C. Imunomarcação de micrometástases de neoplasias mamárias espontâneas em linfonodos de cadelas por meio do receptor CD44. PUBVET, Londrina, V. 6, N. 8, Ed. 195, Art. 1308, 2012.

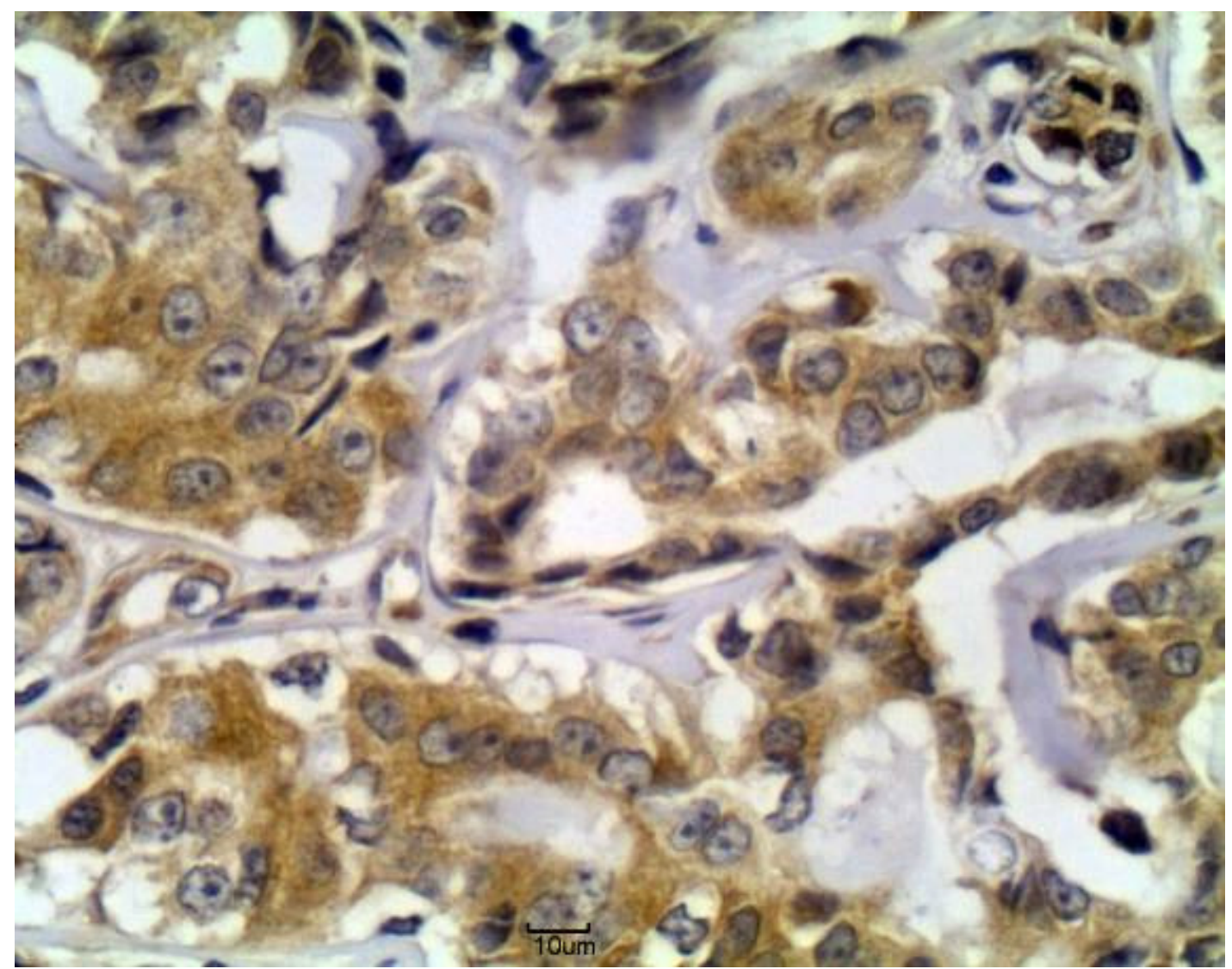

Figura 6: Neoplasia mamária sem metástase em linfonodo de cadela (Grupo N), Marcação imuno-histoquímica para VEGF em citoplasma de células epiteliais neoplásicas. Cromógeno DAB e contracoloração com Hematoxilina de Harris. Obj. 40x.

\section{Discussão}

Em glândulas mamárias, o CD44v6 apresenta forte imunorreatividade em mioepitélio normal e em células epiteliais ductais (FRIEDRICHS, et al. 1995). Em cães a marcação de CD44 em tecidos mamários normais foi maior em ductos e células do epitélio alveolar e em menor quantidade nas células mioepiteliais (PALTIAN, et al. 2009). Em nosso estudo, os sítios primários do tumor apresentaram menor marcação de CD44 em relação à metástase. Contrastando com os nossos achados, POZDNYAKOVA (2008) encontrou mais marcações em sítios primários de CD44v6 do que na metástase cutânea em humanos. Apesar de ser o mesmo clone do anticorpo, a metástase foi 
MAGALHÃES, G.M., SILVEIRA, A.C.T. e ALESSI, A.C. Imunomarcação de micrometástases de neoplasias mamárias espontâneas em linfonodos de cadelas por meio do receptor CD44. PUBVET, Londrina, V. 6, N. 8, Ed. 195, Art. 1308, 2012.

analisada em pele, enquanto o presente estudo analisou linfonodo. Nos linfonodos a maioria dos tumores metastáticos localizava-se nos seios subcapsulares condizendo com a circulação linfática unidirecional, chegando pelos vasos aferentes e saindo pelos linfáticos do hilo, ou eferentes (JUNQUEIRA \& CARNEIRO, 1999). A marcação superexpressa em células no interior de vasos linfáticos confere uma estabilidade na estrutura do êmbolo tumoral (MADRAZO, et al. 2009). Fato interessante observado é que a molécula de adesão CD44 marcou uma média de $73,7 \%$ das células tumorais nos locais das metástases, indicando que a célula neoplásica necessita de adesão para enfrentar o novo microambiente que está colonizando. Muitos estudos em humanos têm proposto que o CD44 pode ser uma molécula de fator prognóstico de metástase (XIN et al., 2001). Em cães, há necessidade de estudos complementares para que fique clara essa hipótese. Segundo os resultados do presente trabalho, a marcação da molécula de adesão CD44 pode ser considerada um fator prognóstico, sendo desfavorável quando há redução em sua expressão em tumores mamários malignos primários (MAGALHÃES et al., 2012).

Uma das funções da molécula CD44 é a ativação de linfócitos T (LOOI et al. 2006). Na resposta inflamatória, o CD44 inicia o caminho primariamente, ativando os linfócitos $T$ para saída dos vasos para vários tecidos inflamados (SIEGELMAN et al, 2000). Os exons V6 e V9 estão envolvidos nessa sinalização de linfócitos (HAMILTON, et al 2007). Como a variante V6 está envolvida tanto na metástase quanto na ativação de linfócitos, autores tentam relacionar o mecanismo pelo qual o CD44 ativa linfócitos T para o local da inflamação com o mecanismo das células tumorais para o local da metástase (HERRLICH et al. 1993). Neste estudo, a marcação em linfócitos T em linfonodos negativos para metástase foi significantemente maior do que a marcação em linfonodos positivos para a metástase. Este resultado sugere que a resposta imune pode estar envolvida no processo de metástase. As respostas imunes adaptativas são mediadas por anticorpos e por linfócitos $T$, que compõem os mecanismos efetores capazes de matar células tumorais "in vitro" (ABBAS et al., 2000). 
MAGALHÃES, G.M., SILVEIRA, A.C.T. e ALESSI, A.C. Imunomarcação de micrometástases de neoplasias mamárias espontâneas em linfonodos de cadelas por meio do receptor CD44. PUBVET, Londrina, V. 6, N. 8, Ed. 195, Art. 1308, 2012.

Provavelmente, quando a molécula CD44 está envolvida na metástase há uma diminuição de linfócitos $T$, pois estes atuam como agressores das células tumorais, impedindo a sua sobrevivência. Até o presente momento não se encontrou estudos associando o CD44 com a metástase e linfócitos T. Postulase aqui ser o linfócito $T$ um fator indicativo de prognóstico. A reduzida ou nula marcação de linfócitos $T$ pelo CD44v6 em linfonodos drenantes de tumores mamários pode ser indicativo de futura presença de metástase. Ao contrário, se houver marcação abundante de linfócitos $T$, provavelmente não haveria metástase nesse linfonodo por este tumor.

Um dos objetivos deste trabalho foi comparar a marcação da molécula de adesão CD44 em tumores mamários malignos caninos com suas respectivas metástases tentando relacioná-las com fatores prognósticos já conhecidos. Estudos in vitro sugerem que o CD44 desempenha um papel importante na migração e invasão tumoral. No entanto, a complexidade dessa molécula, por apresentar várias isoformas, tem causado dificuldades em apresentar respostas a esse respeito. Assim, há várias explicações na literatura científica (LOOI et al., 2006). A investigação do envolvimento da molécula de adesão CD44 com outros mecanismos celulares certamente contribuirá para o avanço da pesquisa com câncer (LOOI et al., 2006). Recentemente, autores mostram que há uma interação do CD44 com a MMP-9 na promoção da metástase. Peng et al. (2007) relataram que o CD44 induz a expressão de MMP-9 nas membranas celulares de células neoplásicas mamárias e que os receptores de CD44 são usados como locais de distribuição de MMP-9, para esta exercer a sua atividade proteolítica, estimulando assim a metástase. Neste estudo, observou-se que houve um aumento de marcação tanto do CD44 quanto da MMP-9 nos locais da metástase, sugerindo que essas moléculas podem estar agindo concomitantemente na metástase. Em relação a E-caderina, embora autores relatem que alta expressão desta possa inibir a ligação do CD44 com o HA, diminuindo assim a motilidade celular (YIN \& QIN, 2003), neste estudo, o aumento da E-caderina e da molécula de adesão CD44 foi significativo $(p<0,05)$ tanto em relação ao grupo $N$ para o grupo $M$ e também do sítio 
MAGALHÃES, G.M., SILVEIRA, A.C.T. e ALESSI, A.C. Imunomarcação de micrometástases de neoplasias mamárias espontâneas em linfonodos de cadelas por meio do receptor CD44. PUBVET, Londrina, V. 6, N. 8, Ed. 195, Art. 1308, 2012.

primário para a respectiva metástase, sendo ambas importantes nesse processo. As marcações para o anticorpo VEGF não apresentaram diferenças significativas em nenhum dos grupos. Tanto as marcações no grupo N como no M foram relativamente altas. Embora seja um pequeno aumento e não significativo por métodos estatísticos parece haver a formação de novos vasos nos locais da metástase do que em tumores malignos primários. Talvez o CD44 possa estar interferindo neste aumento: como já foi descrito, o CD44 pode ser uma molécula promissora na modulação da angiogênese (LOOI et al., 2006)

\section{Referências}

ABBAS, A.K.; LICHTMAN, A.H.; POBER, J.S. Celular and Molecular immunology. 4th edition, Saunders: Philadelphia, p. 553, 2000.

BOURGUIGNON, L.Y.W., SINGLETON, P.A., ZHU, H.; DIEDRICH, F. Hyaluronan-mediated CD44 iterection with RhoGEF and Rho kinase promotes Grb2-associated binder-1 phosphorylation and phosphatidylinositol 3-kinase signaling leading to cytokine (macrophage-colony stimulating factor) production and breast tumor progression. Journal of Biological Chemistry, v.278, p.29420-34, 2003.

DIAZ, L.K.; ZHOU, X.; WRIGHT, E.T.; CRISTOFANILLI, M.; SMITH, T.; YANG, Y.; SNEIGE, N.; SAHIN, A.; GILCREASE, M.Z. CD44 expression is associated with increased survival in node negative invasive breast carcinoma. Clinical Cancer Research, v.11, n.9, p. 3309-14., 2005.

FRIEDRICHS, K.; FRANKE, F.; LISBOA, B. W.; KUGLER, G.; GILE, I. TERPE, H. J.; HOLZEL, F.; MAASS, H.; AND GUNTHERT U. CD44 isoforms Correlate with Cellular Differentiation but not with prognosis in Human Breast Cancer. Cancer Research, v.55, p. 5424-5433, 1995.

GOTTE, M.; AND YIP, G.W. Heparanase, Hyaluronan, and CD44 in Cancers: A Breast Carcinoma Perspective. Cancer Research v. 66, n. 21, 2006; November 1, 2006.

HAMILTON, S.R.; FARD, S.F.; PAIWAND, F.F.; TOLG, C.; VEISEH, M.; WANG, C.; MACCARTHY, J.B.; BISSEL, M.J.; KOROPATNICK, J.; TURLEY, E.A. The hyaluronan receptors CD44 and Rhamm (CD168) Form Complexes with ERK1, 2 That sustain high basal motility in breast cancer cells. The Journal of Biological chemistry, v.262, n.22, p.16667-80, 2007.

HARRELL, J.C.; DYE, W.W.;ALLRED, D.C.; JEDLICKA, P.,.SPOELSTRA, N.S.; SARTORIUS, C.A.; AND HORWITZ, K.B. Estrogen Receptor Positive Breast Cancer Metastasis: Altered Hormonal Sensitivity and Tumor Aggressiveness in Lymphatic Vessels and Lymph Nodes. Cancer Research v.66, n.18, September 15, 2006.

HEBBARD, L.; STEFFEN, A.; ZAWADZKI, V.; FIEBER, C.; HOWELLS,N.; MOLL, J.PONTA,H.; HOFMANN, M.; AND SLEEMAN||, J. CD44 expression and regulation during mammary gland development and function. Journal of Cell Science v.113, p.2618-2630, 2000. 
HERRLICH, P.; ZOLLER, M.; PALS, S.T.; PONTA, H. CD44 slice variants: metastases meet lymphocytes. Immunology Today, v. 14, n. 8, p.395-398, 1993.

HSU, S.M.; RAINE, L.; FANGER, H.A. A Comparative study of peroxidase- antiperoxidase method and an avidin biotin complex method for studying polypeptide hormones with radioimmunuoassay antibodies. American Journal of Clinical Pathology, v. 75, p. 734$738,1981$.

JUNQUEIRA L.C.; CARNEIRO, J. in Histologia Básica, Ed.Guanabara, nona edição, $427 p, 1999$.

KLINGBEIL, P.; NATRAJAN, R.;EVERITT, G.; VATCHEVA, R.; MARCHIO, C.;PALACIOS, J.;BUERGER, H.;.REIS-FILHO, J.S.;.ISACKE, C.M. CD44 is over expressed in basal-like breast cancers but is not a driver of $11 \mathrm{p} 13$ amplification. Breast Cancer Research and Treatment. P.95-109, 2009.

KUO,Y-C.; SU, C-H.; LIU, C-Y. ; CHEN, T-H. ; CHEN, C-P. ; WANG, H-S. Transforming growth factor-b induces $C D 44$ cleavage that promotes migration of MDA-MB-435s cells through the up-regulation of membrane type1-matrix metalloproteinase. International.Journal of.Cancer. v. 124, p. 2568-2576, 2009.

LOOI, L.M.; CHEAH, P.L.; ZHAO, W.; NG, M.H.; YIP, C.H. CD44 expression and axillary lymph node metastasis in infiltrating ductal carcinoma of the breast. Malaysian Journal Pathology, v. 28, n. 2, p. 83086, 2006

MADRAZO, J.; GARCIA-FERNANDEZ, R.A.; GARCIA-IGLESIAS, M.J.; DURAN, A.J.; ESPINOSA, J.; PEREZ-MARTINEZ, C. The role of CD44 adhesion factor in canine mammary carcinomas. The Veterinary Journal. V. 180, p. 371-376, 2009.

MAGALHÃES, G.M.; TROMPIERI-SILVEIRA, A.C.; MUNARI, D.P.; ALESSI, A.C. BEHAVIOR OF CD44 RECEPTORS IN MAMMARY TUMORS OF DOGS. Open Journal of Veterinary Medicine, v.03, n. 01. 2012. In press.

MISDORP, H.; ELSE, R.; HELLMAN, E., Histologic classification of mammary tumors of the dog and cat. In: World Health Organization Internacional Histological Classification of Tumors of Domestic Animals, Series 2, v. 7, no 2, Armed Forces Institute of Pathology Washington DC, 1999.

NAOR, D.; SIONOV, R.V.; ISH-SHALOM, D. CD44: structure, function, and association with the malignant process. Advances in Cancer Research. v. 71, p. 241-319, 1997.

PACOR,S.; ZORZET, S.; COCCHIETTO, M.; BACAC, M.; VADORI, M.; TURRIN, C.; GAVA, B.; CASTELLARIN, A.; AND SAVA, G. Intratumoral NAMI-A Treatment Trigger Metastasis Reduction, Which Correlates to CD44 Regulation and Tumor Infiltrating Lymphocyte Recruitment. The Journal of Pharmacologyand Experimental Therapeutics. v.3, n.2, p. 737-744, 2004.

PALTIAN,V.; ALLDINGER,S.; BAUMGARTNER, W.; WOHLSEIN, P. Expression of CD44 in Canine Mammary Tumours. Journal of Comparative Pathology. v.141, p. 237-247,2009.

PENG,S. T.; SU, C.H.; KUO, C.C.; SHAW, C.F. , WANG, H.S. CD44 crosslinking-mediated matrix metalloproteinase- 9 relocation in breast tumor cells leads to enhanced metastasis. International Journal Of Oncology v.31, p. 1119-1126, 2007 
POZDNYAKOVA, O.; HOANG, M.M.; DRESSER, K.A.; MAHALINGAM, M. Prognostic value of Ecadherin, beta-catenin, CD44v6, and HER2/neu in metastatic cutaneous adenocarcinoma. Archives of Pathology and Laboratory Medice. V. 133, n. 8, p.1285-90, 2009.

SHERIDAN, C.; KISHIMOTO, H.; FUCHS, R. K.; MEHROTRA, S.; BHAT-NAKSHATRI, P.; TURNER, C.H.; GOULET, JR R.; BADVE, S.; NAKSHATRI, H. CD44+/CD24- breast cancer cells exhibit enhanced invasive properties: an early step necessary for metastasis. Breast Cancer Research, v.8, n.5, p, R59. 2006.

SIEGELMAN, M.H.; STANESCU, D.; ESTESS, P. The CD44- iniciated pathway of T-cell extravasasion uses VLA-4 but not LFA-1 for firm adhesion. Journal of Clinocal Investigation, v. 105, p. 683-691, 2000.

XIN Y, GRACE A, GALLAGHER MM, CURRAN BT, LEADER MB, KAY EW. CD44V6 in gastric carcinoma: a marker of tumor progression. Applied Immunohistochemistry Molecular Morphology, v. 9, n. 2, p. 138-142, 2001.

YIN, X,; QIN, Y. E- caderin negativaly regulates CD44- Hyaluronan interection and CD44 mediated tumor invasion and branching morphogenesis. The Journal of biological chemistry, v. 278, n.10, p.8661-68, 2003. 